\title{
Culture, language and niche publications in South Africa
}

\author{
Pedro Diederichs
}

When speaking about culture in South Africa, we as South Africans tend to emphasise the wide variety of peoples that make up our population. We like to point out how different we are, but at the same time how we accept that we are all South Africans. And sooner or later we go on a bit about the Rainbow Nation and how successfully we integrated. We usually end discussions on this topic with how we find unity in our variety: as if this is a great achievement and unique to South Africa alone. But let us remember that we are not that unusual.

If we look at languages as one of the integral parts of any nation's culture, our 11 official languages are not doing too well when it comes to creating unity amongst us. Especially as one of them, Afrikaans, is branded as the language of the oppressor, thereby arousing emotions of hate and pride in different sections of the population. As a compromise, we have opted for English as the country's lingua franca to bridge this problem, which is strange, indeed, from a cultural viewpoint as English was the language of the oppressor of all South Africans in colonial times.

Be this as it may, our cultural history has been formed by masters and servants. Publications in English and Dutch, since the 1800s, initially served the cultures of the colonialists, but a South African flavour slowly began to emerge. As locals became more involved and wiser to the intricacies of print, they started to tell the South African story from their perspective as well. Some spoke in their own language - like the Du Toits, the Prellers, the Jabavus, the Dubes and the Plaatjes to name a few.

This is where I want to link up with my topic of culture, language and publications in niche areas. Niche areas in the publication world have been described as '...the place where a clearly identifiable segment of the consumer market has unfulfilled potential, and hence a gap to fill with expendable income' (Addison, 2002). The local reader market was thus identified and developed throughout the years. In various stages of the country's history these developments played out differently, but even today we experience the market forces of niche areas and preferences that can be traced back to certain cultures in South Africa.

It is precisely these elements that must be put into perspective in any curriculum for the training of the South African journalists of tomorrow. To ignore the roots of where the core niche area consumers come from, spells ruin. Large numbers of failed publications are proof hereof. When these cores are correctly identified, success results, as we still see today. Although at first not taken seriously, The Daily Sun, The Daily Voice and Die Son are proven success stories amidst the circulation wars of South Africa. They need to be viewed seriously as successful communication channels for their kind of readers in their kind of news and information niches.

I have studied the rise (and fortunately not yet the fall) of the Afrikaans newspapers. It was fascinating to see how the cultural and political will of the Afrikaner audience supported the growth and wealth of companies that concentrated on 'roots' - elements that Afrikaners identified with. It is probably one of the great frustrations today for the South African newspaper world - what is it that 
makes the average South African what he is? Who is he? What do we really look like? Questions news people have to ask themselves constantly to be able to work out what will sell their newspapers. Identify? Yes, Deon du Plessis identifies his newspaper with the man in the blue overall. And look what new life that brought to the sorry shores of the newspaper circulation scene in South Africa.

Afrikaans editors are worried about their domination of the niche area of Afrikaans readers. They agree that it is out of loyalty to the language only that lots of readers support the Afrikaans newspapers. What happens if the language loses ground to English and readerships dwindle because of the Afrikaner diaspora?

Die Son has shown that there is still an exploitable market niche out there. It did this with a complete overhaul of layout, writing style and specific story themes. They constantly ask what their readers want.

But this positive occurrence, if all is told, will not necessarily save all the Afrikaans newspapers. There is more to it because within the so-called niche of language, there are other readership niches. The imagination, interest, curiosity, involvement, call it what you like, of the traditional readers of the older titles must be revived.

Consider how Afrikaans music took off and maintains its profile? What happened there? What about all the volks en kultuurfeeste like KKNK and Aardklop and others that are huge successes? But where are the Afrikaans newspapers in this revival? They sponsor and they promote, but this does not appear to bring in the magic circulation figures. More aggressive marketing might be the answer. Maybe editors or journalists must become more active in public life, more opinionated, more interactive as well. It begs for a closer look.

It is clear that language is central to this revival. The neglect of promoting indigenous languages has been criticised by people of the likes of Pallo Jordan, Minister of Arts and Culture, who said: 'To millions of South Africans ... their languages do not enjoy an equal status despite being recognised as official languages. It is a serious indictment of our society that it is virtually impossible to find a bookshop in any of our shopping malls that distributes literature in the indigenous African languages” (Pansalb - South African Language Board).

But like Afrikaans almost 100 years ago, other indigenous languages are seemingly coming into their own through the printed word. Examples here are seen in the strong growth in circulation figures of newspapers like Isolezwe, Ilanga and Um-Africa in Zulu. Isolezwe shows a healthy advertising/editorial balance. It is an upcoming niche market that cannot be ignored. Looked at against the successful background of the Afrikaans media with its niche publications, other indigenous language groups, will, like Afrikaans, indeed follow the same historical development. If one looks at the radio listeners of, for instance, the biggest station, Zulu Radio, with TV following suit, the vernacular stations are way ahead in listener audiences compared to the English language stations, for example. That is a captive audience, but with literacy increasing in SA it follows that more people should be reading. More may prefer news and information, like entertainment, in their own languages as well.

I am certainly not saying the Afrikaans newspapers are on their way out. On the contrary, it is because of their professional skills that they can still show growth in readership as per the latest figures from AMPS. Their ABC figures have been maintained over years, but it is a fact that they follow the worldwide trend of struggling circulations. Seen against the backdrop of social and economic issues in South Africa, even a positive advertising income based on the high LSMs of their readers may not be enough to save them from going backwards.

The Afrikaans newspaper has a rich history of struggle and involvement in its niche reader market of approximately 6 million. In the South African multicultural environment, the Afrikaans press relied heavily on its cultural roots (of which a language struggle formed an integral part) for its 
initial success. It continues to do so.

Is history going to repeat itself for other indigenous language publications?

\begin{abstract}
About the author
Dr Pedro Diederichs is Head of the Department of Journalism at Tshwane University of Technology in Pretoria.
\end{abstract}

Contact: diederichspd@tut.ac.za 